\title{
Homenaje póstumo al doctor Patiño (QEPD)
}

\author{
Tribute to Doctor Patiño (RIP)
}

\author{
Hernando Abaúnza, MD, FACS (Hon), MACC (Hon) \\ Expresidente Asociación Colombiana de Cirugía \\ Ex Director Ejecutivo, Asociación Colombiana de Cirugía \\ Expresidente Federación Latinoamericana de Cirugía - FELAC \\ Ex Director Ejecutivo, Federación Latinoamericana de Cirugía - FELAC
}

Discurso presentado en la Sesión inaugural del Congreso Semana Quirúrgica Nacional 2020 de
la Asociación Colombiana de Cirugía. Bogotá, D.C, Colombia. Noviembre 13 de 2020.

El doctor José Félix Patiño fue hijo del profesor Luis Patiño Camargo y de doña Anita Restrepo de Patiño.

Los médicos que tuvimos la inmensa fortuna de tener como profesor de Clínica Tropical al profesor Patiño Camargo, en el viejo hospital San Juan de Dios en Bogotá, más específicamente en el pabellón Carrión, damos fe de las dotes de erudición, de sabiduría, pero también de autoridad y cariño con sus pacientes y con sus alumnos. iQué afortunados fuimos de tener al profesor Luisito como nuestro maestro!

El doctor José Félix Patiño nació el 15 de febrero de 1927 en San Cristóbal, Venezuela, ya que en ese entonces su padre había sido enviado por la Fundación Rockefeller a investigar la fiebre amarilla en los departamentos de Santander de Colombia y en el Táchira de Venezuela. Fue bautizado en la ciudad de Cúcuta, comenzó sus estudios de primaria en el Colegio Alemán de Bogotá, pero cuando estalló la Segunda Guerra Mundial, Colombia le declaró la guerra a Alemania y la mayor parte de los alumnos salieron del Colegio Alemán. Sus padres lo trasladaron al Gimnasio Moderno, regentado por esa legendaria persona de la educación colombiana, don Agustín Nieto Caballero.

Al terminar su bachillerato, el doctor José Félix ingresó a la Facultad de Medicina de la Universidad Nacional de Bogotá, y mientras cursaba el cuarto año de medicina, en 1948, sucedió el revolucionario 9 de abril, con el consecuente cierre de la Universidad Nacional por algún tiempo. Fue entonces cuando su padre le recomendó continuar sus estudios médicos en los Estados Unidos, $\mathrm{y}$ aunque fue admitido en varias universidades, como Harvard y Berkeley, decidió ingresar a la Universidad de Yale en New Haven.

¿Por qué resolvió el doctor José Félix ingresar a Yale? Según versión propia, escogió la Universidad de Yale ya que tenía el texto de neurofisiología de John Fulton, profesor de esa materia en dicha Universidad, un libro que lo tenía totalmente subyugado. Y vean ustedes la coincidencia: al ingresar a Yale, mientras hacía su inscripción universitaria, tenía ese libro en sus manos y la secretaria de Yale le preguntó ¿por qué tienes ese libro? Respondiendo, porque estoy encantado con él. La secretaria le abrió una puerta y le dijo: "ingrese ahí, el que

Fecha de recibido: 15/11/2020 - Fecha de aceptación: 24/02/2021 - Fecha de publicación en línea: 03/03/2021

Correspondencia: Hernando Abaúnza. Correo electrónico: hernando.abaunza@ascolcirugia.org

Citar como: Abaúnza H, MD, FACS (Hon), MACC(Hon). Homenaje póstumo al doctor Patiño (QEPD). Rev Colomb Cir. 2021;36:185-7. https://doi.org/10.30944/20117582.900

Este es un artículo de acceso abierto bajo una Licencia Creative Commons - BY-NC-ND https://creativecommons.org/licenses/by-nc$\mathrm{nd} / 4.0 /$ deed.es 
esta sentado en esa biblioteca es el doctor Fulton y él va a ser su mentor". El doctor Fulton le entregó las llaves de la biblioteca y le dijo: "esta oficina y la biblioteca fueron las de Harvey Cushing, quien la usó y fue mi mentor", y he aquí otra extraña coincidencia del destino: el mentor de Cushing fue William Halsted, para mí el gigante de la cirugía.

Al terminar sus estudios médicos le fue entregado el premio Borden por su tesis laureada " $E l$ trasplante de tejido embrionario endocrino". Luego en el hospital Universitario de Yale comenzó su programa de especialización de Cirugía General y Cirugía Cardiovascular, del cual llegó a ser Jefe de Residentes. Es bien conocido el hecho de que, en el año de investigación de la residencia, al ver que a los niños con la Tetralogía de Fallot se les practicaba una cirugía de anastomosis de la arteria subclavia a la arteria pulmonar, que no tenía una adecuada recuperación, se le ocurrió unir la vena cava superior a la arteria pulmonar derecha. Entonces, se lo comentó a su profesor William Glenn, quien al comienzo lo miro escépticamente, pero luego la aceptó y la comenzaron a experimentar, con buenos resultados. Al comienzo la llamaron el "Shunt de Patiño", con el tiempo "Shunt de Patiño-Glenn", luego "Shunt de Glenn-Patiño" y finalmente quedó resumida como "Shunt de Glenn".

Al regresar a Colombia, en 1958, fue nombrado profesor de cirugía en el Hospital San Juan de Dios de la Universidad Nacional en Bogotá, y en el año 1959 fue nombrado Jefe de Cirugía del Hospital de La Samaritana. Relata que muy pronto ingresó al hospital una niña que presentaba la Tetralogía de Fallot y él practicó la operación que había ideado en la Universidad de Yale.

Poco después, en el año de 1962, el presidente de la república, Guillermo León Valencia, lo nombró Ministro de Salud y en 1964 fue nombrado Rector de la Universidad Nacional de Colombia. Es en este periodo (1964 a 1966) cuando el doctor Patiño Restrepo realiza la reconocida "Reforma Patiño" de la Universidad Nacional, que según muchas autoridades "estremeció la educación superior del país, con reformas sustantivas y ejercicio perseverante del diálogo, como política de prioridad".
Es importante recordar que hay un libro que examina de manera minuciosa el periodo del doctor Patiño en la Rectoría de la Universidad Nacional de Colombia, "Reforma Patiño UN 1964-1966: una experiencia de construcción institucional" (Ed. Unibiblos, Bogotá 2006), que fue tesis doctoral de William Lee Magnusson (1923-1970) en Berkeley, Universidad de California, traducida al español por Gabriel Restrepo, autor de amplio estudio prologal, quien señala como cualidad del doctor Patiño Restrepo "una personalidad magnética, con enorme carácter, persistente", que condujo su proyecto universitario con visión de integración y desarrollo.

El doctor Patiño Restrepo estuvo vinculado largo tiempo como cirujano, ejerciendo su práctica profesional en la Clínica de Marly de Bogotá y luego fue fundador y uno de los líderes en el establecimiento de la Fundación Santa Fe de Bogotá, modelo de hospital universitario, donde por largo tiempo desempeñó la jefatura del Departamento de Cirugía y posteriormente se desempeñó como jefe honorario de dicho departamento. Además, participó en la creación de la Facultad de Medicina de la Universidad de los Andes, que tiene como Hospital Universitario a la Fundación Santa Fe de Bogotá.

El doctor José Félix Patiño ocupó gran cantidad de distinguidos cargos, entre ellos, fue director y fundador de la Federación Panamericana de Facultades de Medicina - FEPAFEM, presidente de la Academia Nacional de Medicina, presidente de la Federación Latinoamericana de Cirugía - FELAC, presidente de la Asociación Colombiana de Cirugía y Miembro Honorario del American College of Surgeons, una de las distinciones más importantes a la que puede aspirar un cirujano. Ha sido el único cirujano latinoamericano presidente de la International Society of Surgery, y presidió el Congreso Mundial de Cirugía en Toronto en 1989.

La Universidad Nacional de Colombia creo hace poco la Cátedra Patiño Restrepo, como reconocimiento a la inmensa labor y a la obra académica y científica del doctor José Félix Patiño. El 15 de febrero de 2017 asistimos por invitación del rector de la Universidad Nacional, doctor Ignacio 
Mantilla, a la inauguración del ala de la biblioteca de la Universidad Nacional que lleva su nombre y donde fueron instalados los más de once mil volúmenes donados por el doctor José Félix a esa Universidad, entre los cuales se pueden encontrar "La historia natural de Plinio", así, como sus obras sobre música, especialmente operática, junto con los varios textos que escribió sobre Maria Callas, de la cual, el doctor Patiño era una verdadera autoridad con reconocimiento mundial.
Plagiando a John Cameron, que al escribir en 1997 la biografía de William Halsted, dice: "afortunados los médicos de esa generación que tuvieron a Halsted como compañero, profesor, maestro o mentor". Hoy yo añadiría, más afortunados los que contamos con la fortuna de tener a José Félix Patiño, con estos mismos epítetos de Halsted con sus alumnos, pero con el privilegio de tener esa rara y cada día más escasa cualidad humana de la amistad. Gracias, José Félix Patiño, por tu amistad.

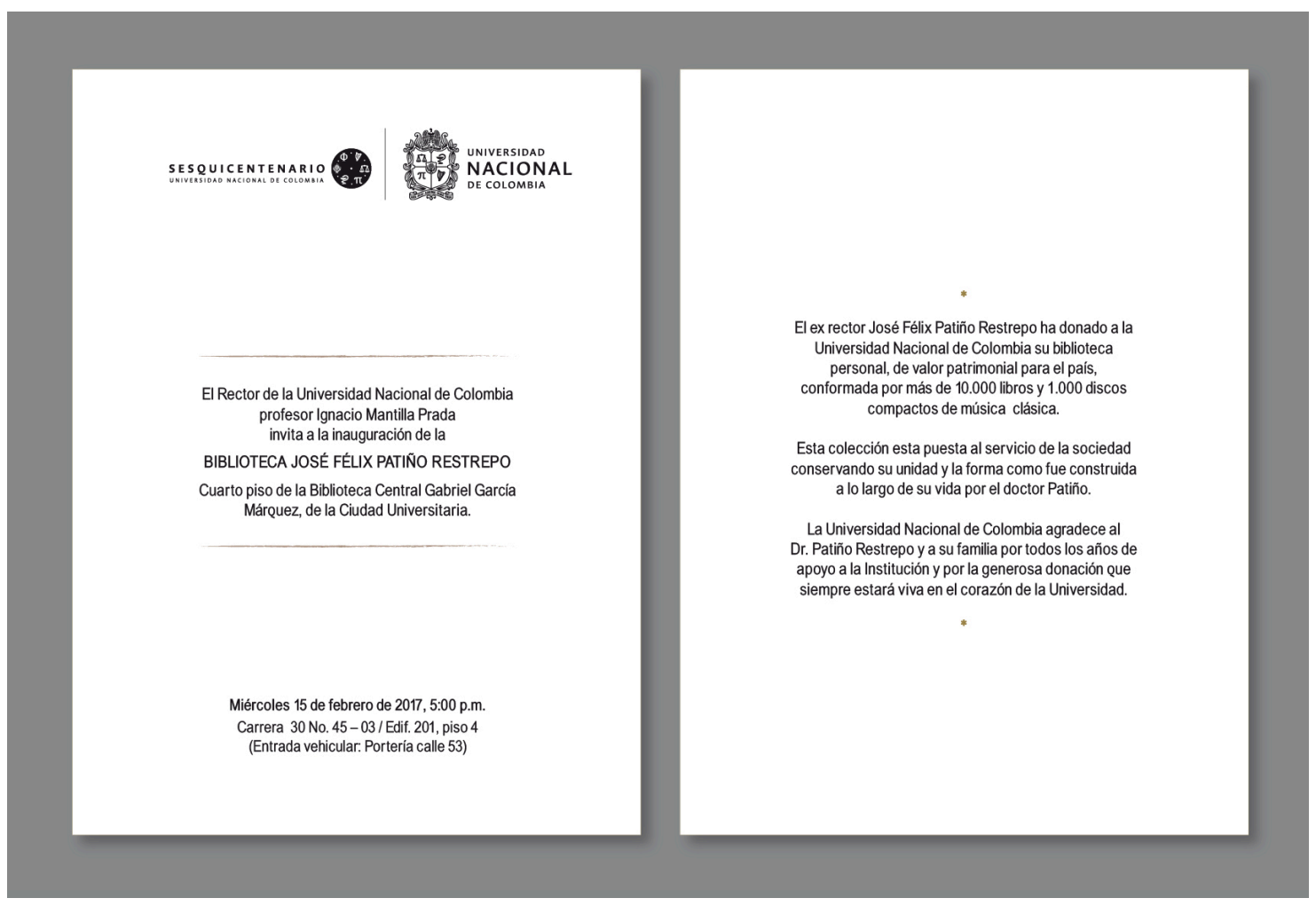

